\title{
West African kenaf (Hibiscus Cannabinus L.) natural fiber composite for application in automotive industry
}

\author{
Tijjani Abdullahi, a, c, " Zawati Harun a, ${ }^{*}$, Mohd Hafiz Dzarfan Othman ${ }^{\text {b }}$, Nasiru Aminu c, Oguntunde \\ Gabriel $^{c}$, Tijjani Aminu c, Siti Aida Ibrahim ${ }^{d}$, Noor Hasliza Kamarudin ${ }^{\text {a }}$
}

a Advanced Manufacturing and Material Center (AMMC), Faculty of Mechanical and Manufacturing Engineering, Universiti Tun Hussein Onn Malaysia, 86400 Parit Raja, Batu Pahat, Johor, Malaysia

b Advanced Membrane Technology Research Centre (AMTEC), Faculty of Chemical and Energy Engineering, Universiti Teknologi Malaysia, 81310 UTM Johor Bahru, Johor, Malaysia

c School of Technology Education, Federal College of Education (Technical) P.M.B. 60 Gombe, Nigeria

d Faculty of Mechanical and Manufacturing Engineering, Universiti Tun Hussein Onn Malaysia, 86400 Parit Raja, Batu Pahat, Johor, Malaysia

* Corresponding author: zawati@uthm.edu.my, abdulltj@gmail.com

\section{Article history}

Received 5 May 2018

Revised 1 June 2018

Accepted 2 July 2018

Published Online 3 December 2018

\section{Graphical abstract}

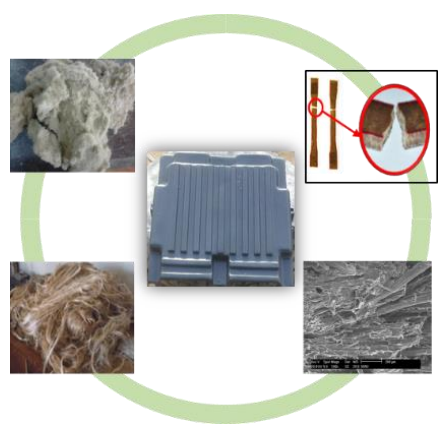

\section{Abstract}

The study of the kenaf core fiber - polymer composites was done by preparing a kenaf/polymer composite using polypropylene (PP) polymer matrix and Scona TPPP 9012 GA as coupling agent with Nigerian grown Kenaf natural fiber through hot pressing. The objective was to characterize the stability and bond strength of the polymer/fiber interface through morphological analysis by using Scanning Electron Microscopy (SEM) as well as the characterization of thermal and mechanical properties of the composite. The result obtained shows an increment in tensile strength as a percentage of kenaf fiber increased to $30 \%$, this trend continuous surprisingly, even at $50 \%$ kenaf fiber loading, which goes against the result obtained in previous literature. Thus, signifying the positive influence of Scona TPPP 9012 GA coupling agent. However, further analysis indicated that $40 \%$ kenaf fiber loading has a better chance to be considered suitable for use in automotive structure.

Keywords: West Africa, kenaf, Nigeria, fiber, composite

\section{INTRODUCTION}

Reinforcing plastic with natural fiber is already a well-established approach to obtaining special composites with useful properties [1, 2], and this concept has been receiving amplified awareness due to the need for replacing fossil - based engineering materials. Among the many natural fiber reinforcements used, the most common and highly sorted for is the kenaf natural fiber. Kenaf plant is an annual crop that can be grown and be harvested within a season, it is a versatile plant that can be grown through diverse weather conditions and geographical locations. Historically, this wonderful plant originated from Africa [3] but the cultivation of this plant has spanned across the Asian countries such as India, Pakistan, China, Indonesia and it has been reported to be gaining attention in Malaysia recently.

Since kenaf is always available in long fiber form, it is found to be useful in many industrial applications such as insulators, seals and car body parts. There are many advantages of using kenaf fiber, such as renewability and biodegradability that is essential for making environmentally friendly products [4]. Others include; acceptable specific strength properties, low cost, low density, high toughness, good thermal properties, reduced dermal and respiratory irritation, ease of separation and reduced tool wear [5, 6].

The industrial feasibility of kenaf fiber for structural value has a very wide coverage. In the automobile industry, kenaf fiber has been used as a replacement for engineered synthetic materials because of its renewability. Mohanty, Drzal [7], Nishino, Hirao [8] has documented the progression made by one of the automobile giants, "The Toyota Motors" in using kenaf blended polypropylene for fabrication of door panels. Further studies on kenaf application in automobile industry by Parikh, Calamari [9], Thilagavathi, Pradeep [10] shows that it has potentials for noise control, weight reduction and also for interior floor covering.

Kenaf is grown in the West African region for its horticultural and socio-economic relevance. The warm season of the West African tropical climate favoured the growth of kenaf plant to about 5 to $6 \mathrm{~m}$ height within the growth period of 6 to 7 months [3]. Although kenaf has proven to be a versatile plant that can be grown across a diverse soil type and geographical locations, it is somewhat delicate to cool temperatures and does not endure hoarfrost. Fig. 1 describes a typical West African variety of kenaf plant at the beginning of its flowering stage.

The cultivation of kenaf plant has been well established in over twenty (20) states of the Nigerian federation [11, 12]. The historical reason behind this high rate of kenaf cultivation can be hinged to the days of the Nigeria Fiber Industries Company Limited (NIFINCO), Nigeria Agro-sacks Company (NASCO) and the Northern Nigeria Fiber Product Limited (NNFP). Regrettably, despite the laudable cultivation rate of kenaf plant and a well-established kenaf fiber processing outfits, kenaf fiber in Nigeria is predominantly utilized in agro-allied industries e.g. agro-sack, twine cordage and rope. 
Additionally, this wonderful plant and its fiber are now mainly utilized for feed (human and animals) and traditional craft in most of the Nigerian rural communities. For the first time in a decade, the Nigerian government launched a campaign to expand the production, processing and high-value industrial utilization of indigenous agricultural products and underutilized mineral resources.

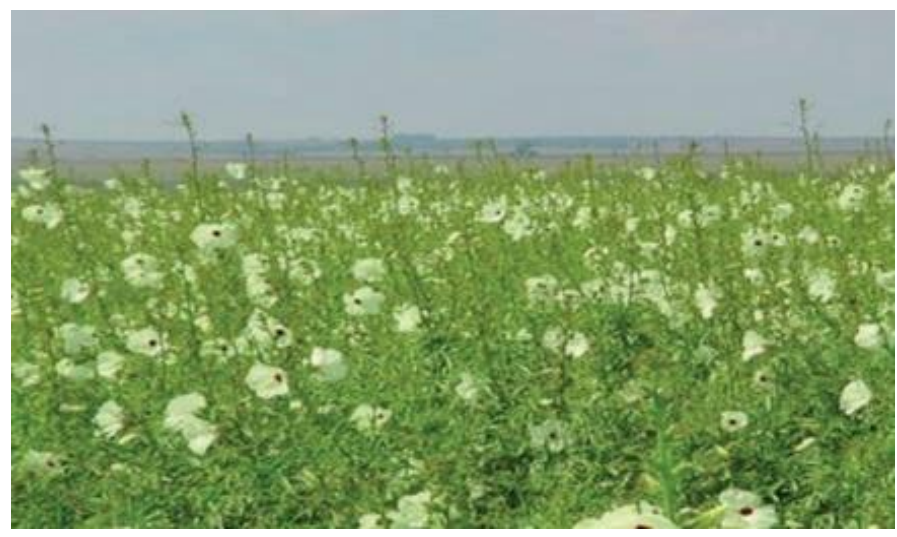

Fig. 1 Pictorial view of the West African variety kenaf plant at early maturity stage.

Thus, this study was conducted towards fulfilling this renewed effort, by preparing a kenaf - polymer composite using polypropylene (PP) polymer matrix and Scona TPPP 9012 GA as coupling agent with Nigerian grown kenaf natural fiber. The objective was to characterize the stability and bond strength of the polymer/fiber interface through morphological analysis by using Scanning Electron Microscopy (SEM) as well as the characterization of mechanical properties of the composite.

\section{METHODOLOGY}

\section{Materials}

The fiber used for this study were kenaf fibers extracted out of the kenaf (Hibiscus cannabinus L.) grown in Nigeria. Prior to the extraction, the kenaf plant was harvested at its early maturity period, a stage which is attained a few months after planting and it is symbolized with flowering as shown in fig.1. The selection of this stage for harvest was informed in accordance with $[13,14]$ thus, recommended that excellent and high-quality fiber is assured from kenaf plants at the flowering stage. The extraction was achieved at the Institute of Agricultural Research and Training (IAR\&T), Ibadan Nigeria and the fiber retting were conducted at the Federal Institute of Industrial Research Oshodi (FIIRO). Polypropylene (PP) resin and Scona TPPP 9012 GA as a coupling agent are both supplied by Ciba Geigy India Ltd.

\section{Specimen preparation}

The extraction of the fiber was done through a mechanical process, followed by water retting to separate the fiber from their stalks using a Controlled System Tank Retting (CSTR) technique for about 10 days. At the end of the water retting process, the fibers were then cleaned with water and dried under $80^{\circ} \mathrm{C}$ for $10 \mathrm{~h}$ in the oven. After drying, the physical, mechanical and chemical evaluation of the fiber was undertaken for a better understanding of the properties. The kenaf was chopped and sifted to get a near uniform short kenaf fibers. A homogenous mixture of kenaf fiber, Polypropylene resin and Scona TPPP 9012 GA was achieved by dispersing the individual fiber in random orientation followed by mixing using two-roll mill under a temperature of $190^{\circ} \mathrm{C}$ and motor speed of $50 \mathrm{rpm}$ for a total period of 10 minutes. $3 \%$ by weight was the concentration of the Scona TPPP 9012 GA coupling agent used based on the recommendation by [15].

Neat composites with varying fiber fraction of $0 \% \mathrm{wt}, 30 \% \mathrm{wt}$, $40 \% \mathrm{wt}$, and $50 \% \mathrm{wt}$ also represented as (K10, K30, K40 and K50) were prepared through a compression molding process according to the formulation composition shown in Table 1.
Table 1 Formulation compositions of the composite.

\begin{tabular}{cccc}
\hline \multicolumn{4}{c}{ Composition \% } \\
\hline $\begin{array}{c}\text { Sample } \\
\text { Code }\end{array}$ & PP & Kenaf & $\begin{array}{c}\text { Scona TPPP } \\
\text { 9012GA }\end{array}$ \\
\hline K0 & 97 & 0 & 3 \\
K30 & 67 & 30 & 3 \\
K40 & 57 & 40 & 3 \\
K50 & 47 & 50 & 3 \\
\hline
\end{tabular}

*Composition was estimated based on dry weight of kenaf fiber

\section{Mechanical testing}

A tensile test was carried out using Universal Testing Machine (Llyod 20kN) at room temperature using a crosshead speed of 2 $\mathrm{mm} / \mathrm{min}$. While the flexural test was carried out using the 3-point technique, the tensile and flexural test was in accordance with ASTM D638-type1 and ASTM D790 respectively as shown in Fig. 2 a, b.

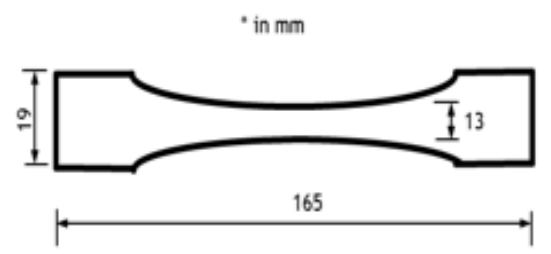

Tensile test

(a)

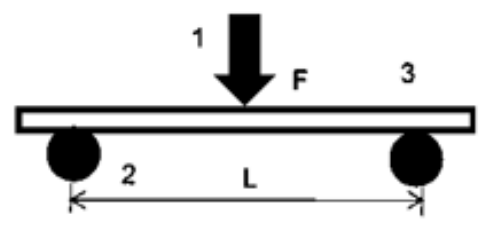

Flexural test

(b)

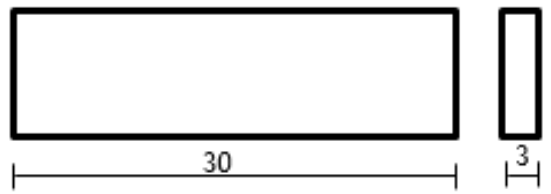

Hardness test

(c)

Fig. 2 Samples for Tensile, Flexural and Hardness test based on ASTM D638-type1 and ASTM D790 respectively.

\section{Hardness testing}

The Rockwell hardness test was chosen for the purpose of this study because it is the best method to measure the hardness scale for plastic material according to ASTM D785. Scale L, a ball with a diameter of $6.35 \mathrm{~mm}$, and a load of $588.4 \mathrm{~N}$ was used as a measuring range between $50-115 \mathrm{HRL}$. The hardness test was conducted on a sample with approximate dimensions of $15 \mathrm{~mm} \times 30 \mathrm{~mm} \times 3 \mathrm{~mm}$ as shown in Fig. 2c, and the hardness value of each composite sample was computed as an average of three areas on each sample.

\section{Density testing}

The density test of the prepared material was performed using 4 pieces of each compounded mixture (K0, K30, K40 and K50) and each specimen was prepared with a size of $20 \mathrm{~mm} \times 20 \mathrm{~mm} \times 20 \mathrm{~mm}$. The specimen was weighed each, on a digital balance and the weights were recorded as the weight $\mathrm{W}(\mathrm{g})$. The specimen is then loaded by means of densometer and dropped on the mercury in a beaker and the volume was recorded as the initial $\mathrm{V}_{1}\left(\mathrm{~cm}^{3}\right)$. The sample was subsequently dipped completely into the liquid (mercury) for a soaking period of 10 
minutes. At the end of the soaking time, the final volume was then recorded as $\mathrm{V}_{2}\left(\mathrm{~cm}^{3}\right)$. The density of the prepared material was determined according to ASTM C493-98 using equation 1

$$
\mathrm{BD}=\frac{\mathrm{W}}{\mathrm{V} 1-\mathrm{V} 2} \mathrm{~g} / \mathrm{cm}^{3}
$$

\section{RESULTS AND DISCUSSION}

\section{Fiber quality evaluation}

After drying, fiber quality evaluation and testing were conducted. Figure 3, shows the SEM morphology of the kenaf fiber. Fig. 2a describes the longitudinal view of the kenaf fiber and Fig. $2 b$ represents the cross-sectional view. It can be seen clearly that the appreciable fiber length was achieved and it is free of stacking.
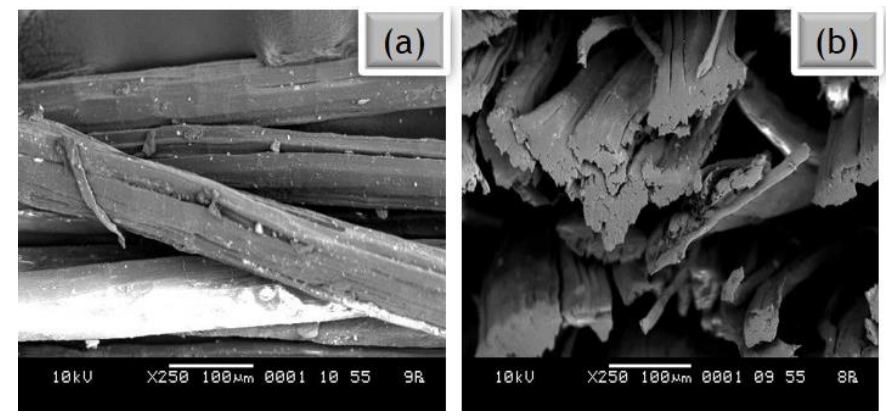

Fig. 3 (a) Longitudinal view and (b) the cross-sectional view of the Nigerian grown kenaf fiber.

The reason for obtaining the considerably clean fiber as shown in figure 2 may be associated with harvesting the kenaf at the early part of its growing cycle [14]. Therefore, it will be valuable to note that a better and favorable fiber can be obtained successfully only when the harvest of the kenaf crop is done at an early growth stage. A careful observation on the surface morphology of the fiber revealed a cleaner fiber surface, with less significant impurities even without further treatment.

Due to differences in species and the unique variety of the West African kenaf plant, as well as the important role which the fiber played in the blended composite, demands a better understanding of properties of the prepared fiber. The results obtained shows that the West African kenaf fiber has $58-61 \%$ cellulose content, Hemicellulose of $18-20$ wt.\% and Lignin of 13.7- 16.2 wt.\%. Based on the speculation by [5, $13,16]$ that, the working properties of natural fibers is generally subjective to the physical structure of the fiber and the amount of cellulose present in the fibers, it is highly anticipated that these exceptional properties recorded will manifest on the fiber quality and invariably on the prepared composite. Table 2 . Presents the mechanical and physical properties of the West African kenaf fiber as obtained after the fiber quality evaluation process.

Table 2 Mechanical and physical properties of West African kenaf fiber.

\begin{tabular}{ll}
\hline \multicolumn{2}{c}{ Mechanical/physical properties } \\
\hline Properties & Value \\
\hline Fiber length $(\mathrm{m})$ & $2.2-3.8$ \\
Fiber diameter $(\mu \mathrm{m})$ & $17.5-22$ \\
Tensile strength $(\mathrm{Mpa})$ & $450-800$ \\
Elongation $(\%)$ & $1.6-2.8$ \\
Young's modulus $(\mathrm{Gpa})$ & $21-45$ \\
Fiber density $\left(\mathrm{g} / \mathrm{cm}^{3}\right)$ & 0.99 \\
Moisture content $(\mathrm{wt} . \%)$ & $9.00-10.2$ \\
Water absorbency $(\%)$ & 0.8 \\
\hline
\end{tabular}

\section{Tensile test analysis}

Four samples were tested for each different composition of kenaf fiber loading $(0 \%, 30 \%, 40 \%$, and $50 \%)$ and the mean values were reported in Table 3, for the purpose of identifying the modulus of elasticity (Young's Modulus), tensile stress, and also their extension.
The average maximum axial load that sample with $0 \%$ kenaf fiber can withstand is about $931 \mathrm{~N}$, and the average tensile strength value of 19.650 MPa, The results further shows an increment in tensile strength as percentage of kenaf fiber increased to $30 \%$ with average tensile strength of $21.794 \mathrm{MPa}$, this trend continuous surprisingly even at $50 \%$ kenaf fiber loading by achieving up to $23.149 \mathrm{MPa}$ average tensile strength, which goes against the result obtained in previous literature [17]. Thus, signifying the positive influence of Scona TPPP 9012 GA coupling agent.

Table 3 Tensile test results for varying percent kenaf fiber loading.

\begin{tabular}{cccccc}
\hline Sample & $\begin{array}{c}\text { Maximum } \\
\text { Load (N) }\end{array}$ & $\begin{array}{c}\text { Extension } \\
\text { at Max. } \\
\text { Load } \\
(\mathbf{m m})\end{array}$ & $\begin{array}{c}\text { Tensile } \\
\text { Stress } \\
\text { at Max. } \\
\text { Load } \\
(\mathbf{M P a})\end{array}$ & $\begin{array}{c}\text { Tensile } \\
\text { Strain at } \\
\text { Max. } \\
\text { Load } \\
(\mathbf{m m} / \mathbf{m m})\end{array}$ & $\begin{array}{c}\text { Modulus } \\
\text { of } \\
\text { Elasticity } \\
(\mathbf{G P a})\end{array}$ \\
\hline $\mathrm{K} 0$ & 931.18 & 1.5842 & $\mathbf{1 9 . 6 5 0}$ & 1.6430 & 1.8260 \\
$\mathrm{~K} 30$ & 967.93 & 1.8781 & $\mathbf{2 1 . 7 9 4}$ & 1.9836 & 1.6144 \\
$\mathrm{~K} 40$ & 1302.6 & 2.9846 & $\mathbf{3 1 . 3 6 7}$ & 3.1499 & 1.3361 \\
$\mathrm{~K} 50$ & 881.42 & 4.4841 & $\mathbf{2 3 . 1 4 9}$ & 4.8190 & 0.7925 \\
\hline
\end{tabular}

However, Fig. 4 indicated that $40 \%$ kenaf fiber loading with an average tensile strength value of $31.367 \mathrm{MPa}$, has a better chance to be considered suitable for use in automotive structure. This assertion can be clearly substantiated comparing the result of tensile strength (MPa) against the percentage of kenaf fiber using Scona TPPP 9012 GA and Epolene 43 [18] Fig. 5, where there is about 45\% increase of the tensile strength recorded.

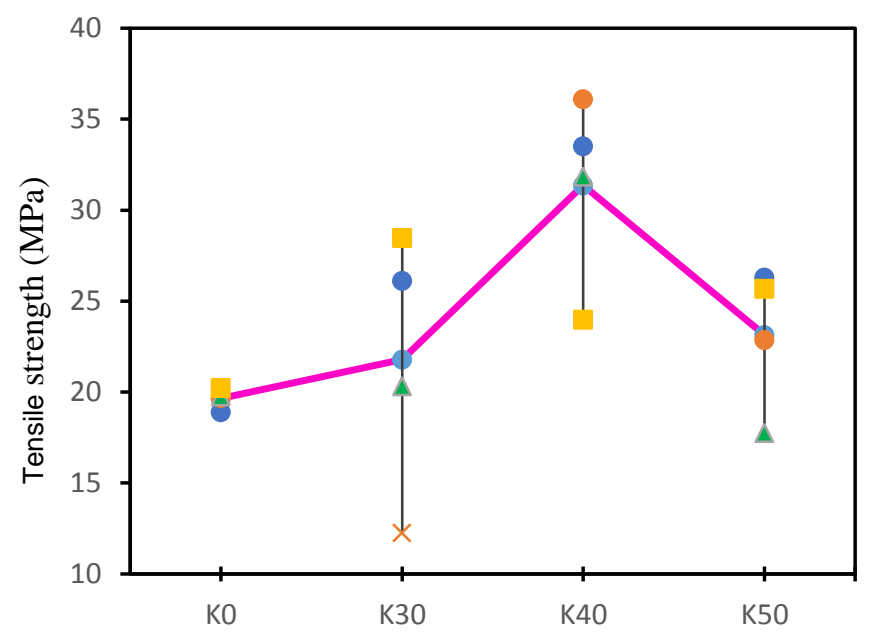

Fiber loading, wt $\%$

Fig. 4 Tensile strength against the percentage of kenaf fiber loading and the average for each sample.

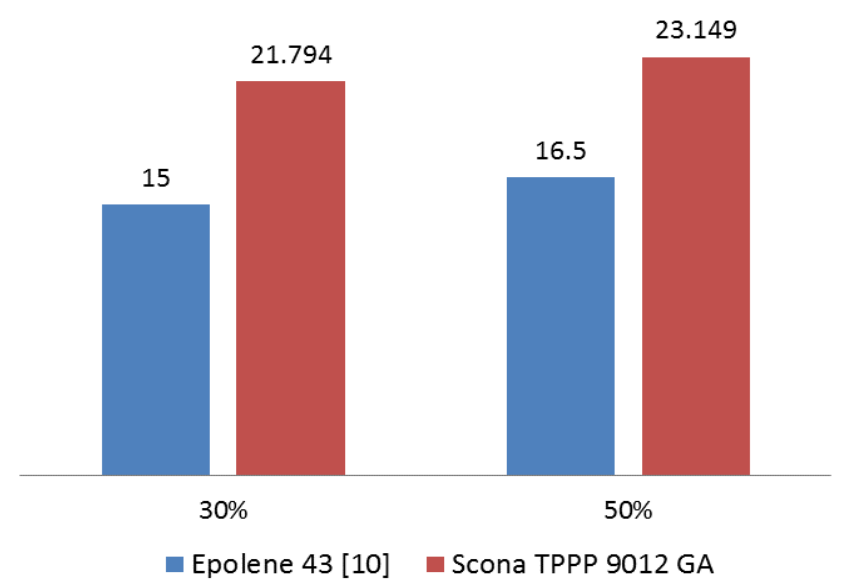

Fig. 5 Comparison of tensile strength against the percentage of kenaf fiber using Scona TPPP 9012 GA and Epolene 43. 
The thorough analysis shows that failure of all the tensile test specimens' does not occur in the middle of the specimen Fig. 6, and there were distorted outlines at the failure edges showing a better interfacial bonding between the fiber and the matrix. More description as contained in the graph of stress against the extension for $0 \%, 30 \%$, $40 \%$, and $50 \%$ kenaf fiber (not presented here), affirmed that all the specimens break at the plastic region which represents plastic behavior.

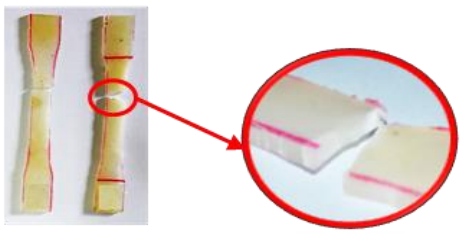

$0 \%$ Kenaf loading

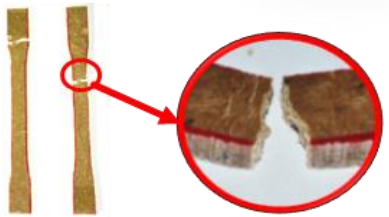

$40 \%$ Kenaf loading

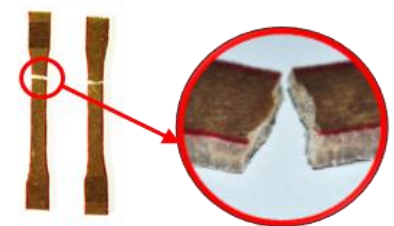

$30 \%$ Kenaf loading

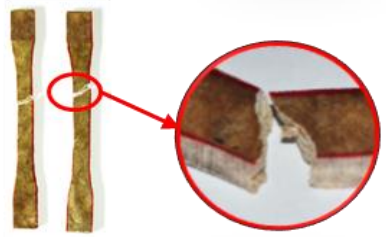

$50 \%$ Kenaf loading
Fig. 6 Failure surface of tensile test specimens.

\section{Flexural test analysis}

The flexural test was carried out using the 3-point technique in accordance to ASTM D790, the average flexural modulus and strength of three samples of each composition $(0 \%, 30 \%, 40 \%$ and $50 \%)$ were calculated and presented in Fig. 7. The result shows that the flexural modulus of the composite is slightly above $2 \mathrm{GPa}$ at $40 \%$ fiber loading resulting from adequate homogeneity between the matrix and orientation of the kenaf fiber.

However, at 50\% kenaf fiber loading, the composite flexural modulus decrease to $1.9 \mathrm{GPa}$, and the reason may be attributed to poor alignment of the fiber in the matrix since the fiber seems to be over saturated in the matrix at that loading percent. Thus, resulting in the formation of bubbles during mixing, which promotes a negative effect on the composite.

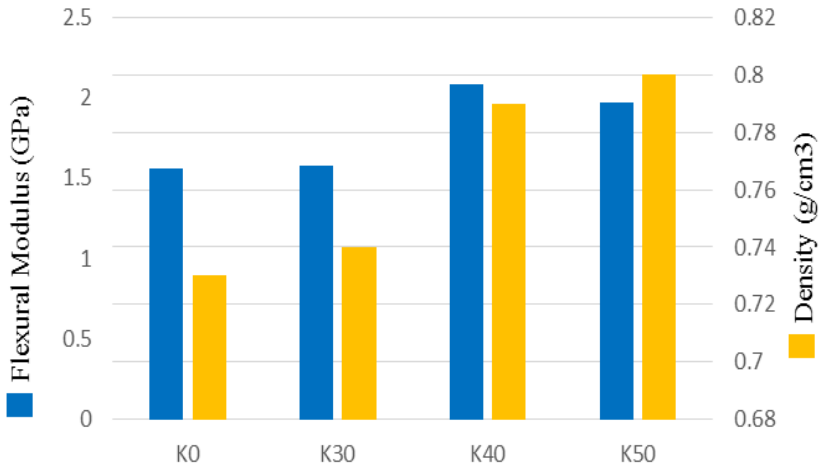

Fiber loading, wt $\%$

Fig. 7 SEM images of kenaf reinforced polypropylene composites.

In addition, Fig. 7, revealed that the density of the composite increases with the increase of fiber loading. Further observation on the result showed that a correlative relationship does exist between the density of the specimen and the fiber loading in which the density increased with the increase in fiber loading. Thus, the fiber as a filer material has outstanding properties which influenced the composite material to become denser and structurally excellent for the structural and semi-structural application. It can be observed that the best correlation was at $40 \%$ fiber loading because the sample was able to record an increased density value of $0.79 \mathrm{~g} / \mathrm{cm} 3$ without lowering the flexural properties and the tensile strength as shown in Fig. 4. However, such increase in density does not defeat the goal of the natural fiber composite towards achieving a less weight material for automotive body parts. Juan, Naughton [19] Conducted a performance simulation of instrument panels made of polypropylene and declared that it is essential for the bumper materials to have the flexural modulus more than $2.1 \mathrm{GPa}$. Hence, this developed composite at $40 \%$ kenaf fiber loading has the required flexural strength to be used for fabrication of car body panels.

\section{Hardness test analysis}

The hardness of the composite was evaluated using Rockwell Hardness Tester LS - 200II PR machine, in accordance to ASTM D785 standard. The purpose of conducting this test was to study the degree of hardness of the composite in relation to the different fiber loading regime. This test used scale $\mathrm{L}$, a ball with a diameter of $6.35 \mathrm{~mm}$, and a load of $588.4 \mathrm{~N}$. The measuring range was between $50-115 \mathrm{HRL}$, and was performed at three different points on each specimen. Four samples were tested and the achieved hardness values were reported in Table 4 and discussed in the subsequent paragraphs.

Table 4 Rockwell hardness test results.

\begin{tabular}{|c|c|c|c|}
\hline \multicolumn{4}{|c|}{ Rockwell Hardness Test (HRL) } \\
\hline $\begin{array}{l}\text { Kenaf } \\
\text { Fiber }\end{array}$ & Sample & $\begin{array}{l}\text { Hardness } \\
\text { Value }\end{array}$ & $\begin{array}{l}\text { Average } \\
\text { Value of } \\
\text { Hardness }\end{array}$ \\
\hline \multirow{4}{*}{ K0 } & KO A & 78 & \multirow{4}{*}{$64.5 \mathrm{HRL}$} \\
\hline & K0 B & 62 & \\
\hline & K0 C & 54 & \\
\hline & KO D & 64 & \\
\hline \multirow{4}{*}{ K30 } & K30 A & 81 & \multirow{4}{*}{$80.00 \mathrm{HRL}$} \\
\hline & K30 B & 80 & \\
\hline & K30 C & 79 & \\
\hline & K30 D & 80 & \\
\hline \multirow{4}{*}{ K40 } & $\mathrm{K} 40 \mathrm{~A}$ & 80 & \multirow{4}{*}{ 82.75 HRL } \\
\hline & K40 B & 84 & \\
\hline & K40 C & 85 & \\
\hline & K40 D & 82 & \\
\hline \multirow{4}{*}{ K50 } & K50 A & 81 & \multirow{4}{*}{$83.00 \mathrm{HRL}$} \\
\hline & K50 B & 84 & \\
\hline & K50 C & 84 & \\
\hline & K50 D & 83 & \\
\hline
\end{tabular}

Table 4 shows the recorded value of hardness of four (4) composite samples for each different composition of kenaf fiber loading which were $0 \%, 30 \%, 40 \%$, and $50 \%$ respectively. As the percentage of kenaf fiber increases to $30 \%$, there is a high increment in the hardness of the composite which can be attached on to the effect of the adequate mixing process and the even distribution of the kenaf fiber, and also due to proper adhesion of the matrix onto the fiber [20].

Meanwhile, the increase of kenaf fiber loading from $30 \%$ to $40 \%$ and $50 \%$, resulted in a slight increment in the value of hardness, which may be possible due to the saturation effect of fiber on the matrix as earlier noted by [21] that hardness activities in a fiber/polymer composite is a product of the relative fiber volume and modulus. Fig. 8 , describes the average hardness value of all tested samples based on different fiber loading percent which were $64.5,80,82.75$, and 83.00 HRL respectively.

Considering the average hardness value of $82.75 \mathrm{HRL}$ obtained for K40 samples indicates that K40 formulation proved to be the most suitable mixture that can produce a kenaf/polymer composite with a 
suitable surface hardness without diminishing the tensile nor the flexural modulus of the composite.

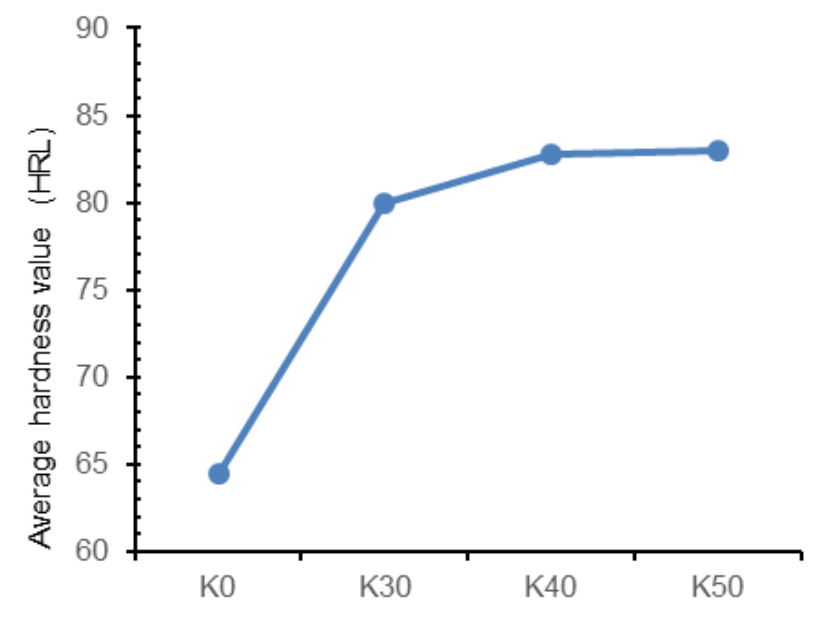

Fiber loading, wt $\%$

Fig. 8 Average hardness value (HRL) against percentage of kenaf fiber.

\section{Morphology analysis}

The purpose of this analysis was to study the effect of fiber loading, mixing process and interfacial adhesion between kenaf fiber and matrix, which contributed to the respective tensile strength. It was also to study the failure mechanism, on the tensile failure surface. Figure 9 shows the SEM images of tensile failure surface for K0, K30, K40, and K50 kenaf fiber reinforced composites.

Based on the information derived from Fig. 9, the failure surfaces exhibited different characteristics. 0\% kenaf fiber composite Fig. 9 (K0), shows a reasonably smooth failure surface. Thus, indicating that it has a low-stress energy absorbing mechanism. However, as percentage of kenaf fiber loading increases to $30 \%, 40 \%$, and $50 \%$, the microstructure shows a rougher failure surfaces with fiber tearing, pointing to a better improvement in the strength of the composite, which may be due to uniform distribution and adequate compactness in the dispersion of kenaf fiber into the matrix. From Fig. 9 (K30), there is a number of micro-voids (fiber pullout traces) formed as a result of the detachment of kenaf fiber from the matrix surface.

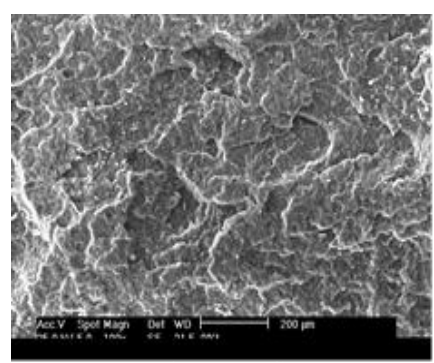

KO

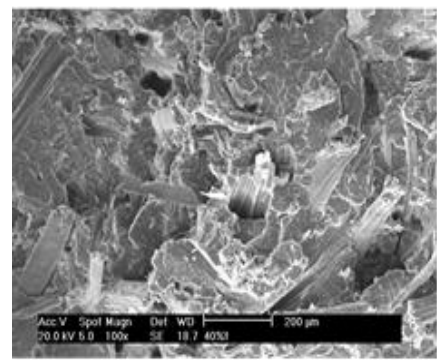

K40

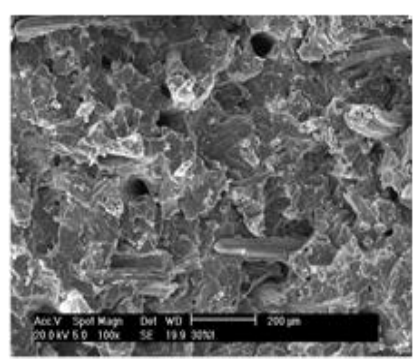

$\mathrm{K} 30$

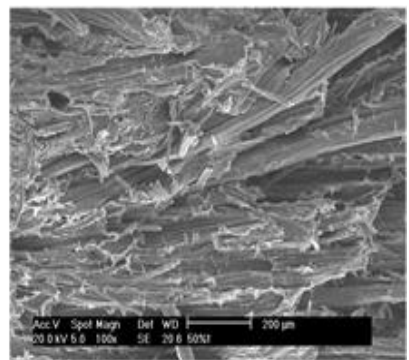

K50
Fig. 9 SEM images of tensile failure surface for $\mathrm{KO}, \mathrm{K} 30$, K40, and $\mathrm{K} 50$ kenaf fiber reinforced composites.
Thus, suggesting a weak interfacial bonding between the fiber and the matrix which translates to the tensile strength of $21.794 \mathrm{MPa}$ and the flexural modulus of $1.58 \mathrm{GPa}$.

When the addition of kenaf fiber reached up to $40 \%$, the microstructure (Fig.9 K40) shows less fiber pullout traces indicating a rapid increment in the tensile strength $(31.367 \mathrm{MPa})$ probably due to the influence of the Scona TPPP 1920 GA which improved the fibermatrix interfacial adhesion between these two components. The result at this parameter was higher and more suitable than the value obtained at $50 \%$ fiber loading, probably as a result of poorly dispersed large fiber content in K50 sample, a situation that might lead to formation microvoids during the compression molding process, a result of poorly dispersed large fiber content in the sample.

\section{CONCLUSION}

The composite has higher tensile strength, flexural strength, and hardness value at $40 \%$ fiber loading. The higher cellulose content and the smaller fiber diameter of the Nigerian grown kenaf fiber, coupled with the additional effect of Scona TPPP 9012 GA were considered significant for the high mechanical properties recorded by the composite. Hence, the $40 \%$ fiber loaded composite has a better chance to be selected for structural applications, especially as a replacement for engineering plastics where the tensile and flexural properties are more important. Nonetheless, the potential application of this developed composite for fabrication of car body panels can be fully explored by taking into consideration the impact strength and water absorption properties of the composite. This paper is proposing a further study on the effect of kenaf fiber particle size on the properties and application of kenaf/polymer composite.

\section{ACKNOWLEDGEMENT}

The authors would like to acknowledge Universiti Tun Hussein Onn Malaysia, Centre for Graduate Studies, ORICC for the Graduate Research Incentive Grant (Vot No: U738), TRGS Vot T001 for partly sponsoring this paper and Tertiary Education Trust Fund (TETFUNDNigeria) Federal College of Education (Technical) Gombe, Nigeria

\section{REFERENCES}

[1] Zaman, H. U., M. A. Khan, R. A. Khan, and D. Beg, A comparative study on the mechanical, degradation and interfacial properties of jute/LLDPE and jute/natural rubber composites. International Journal of Polymeric Materials, 2011. 60(5): p. 303-315.

[2] Zhong, J., H. Li, J. Yu, and T. Tan, Effects of natural fiber surface modification on mechanical properties of poly (lactic acid)(PLA)/sweet sorghum fiber composites. Polymer-Plastics Technology and Engineering, 2011. 50(15): p. 1583-1589.

[3] Alexopoulou, E., Y. Papatheohari, M. Christou, and A. Monti, Origin, description, importance, and cultivation area of kenaf, In Monti A., Alexopoulou E. (Eds.). Kenaf: A multi-purpose crop for several industrial applications (pp. 1-15), 2013. London: Springer.

[4] Jeyanthi, S. and J.J. Rani, Improving mechanical properties by kenaf natural long fiber reinforced composite for automotive structures. Tamkang Journal of Science and Engineering, 2012. 15(3): p. 275-280.

[5] Mohanty, A.K., M. Misra, and L.T. Drzal, Natural fibers, biopolymers, and biocomposites. 2005: CRC Press.

[6] Zampaloni, M., F. Pourboghrat, S. Yankovich, B. Rodgers, J. Moore, L. Drzal, et al., Kenaf natural fiber reinforced polypropylene composites: a discussion on manufacturing problems and solutions. Composites Part A: Applied Science and Manufacturing, 2007. 38(6): p. 1569-1580.

[7] Mohanty, A., L. Drzal, and M. Misra, Novel hybrid coupling agent as an adhesion promoter in natural fiber reinforced powder polypropylene composites. Journal of Materials Science Letters, 2002. 21(23): p. 18851888 .

[8] Nishino, T., K. Hirao, and M. Kotera, X-ray diffraction studies on stress transfer of kenaf reinforced poly (L-lactic acid) composite. Composites Part A: Applied Science and Manufacturing, 2006. 37(12): p. 2269-2273.

[9] Parikh, D., T. Calamari, A. Sawhney, E. Blanchard, F. Screen, J. Myatt, et al., Thermoformable automotive composites containing kenaf and other cellulosic fibers. Textile Research Journal, 2002. 72(8): p. 668-672. 
[10] Thilagavathi, G., E. Pradeep, T. Kannaian, and L. Sasikala, Development of natural fiber nonwovens for application as car interiors for noise control. Journal of Industrial Textiles, 2010. 39(3): p. 267-278.

[11] Abdullahi, T., Assessment of Renewable Energy Sources for Sustainable Development in Nigeria. Jurnal Teknologi, 2015. 77(12).

[12] Akubueze, E., C. Ezeanyanaso, E. Orekoya, D. Akinboade, F. Oni, S. Muniru, et al., Kenaf fiber (Hibiscus cannabinus L.): A viable alternative to jute fiber (Corchorus genus) for agro-sack production in Nigeria. World Journal of Agricultural Sciences, 2014. 10(6): p. 308-331.

[13] Cho, J., Y. Park, B. Lee, J. Han, and E. Miyashita, Properties of kenaf from various cultivars, growth, and pulping conditions. In Fifth Chemical Congress of North America. 11-15 November. Cancun, Quintana Roo, Mexico, 2001.

[14] Hittersay, P., SA kenaf production holds great promise. Farmer's Weekly (South Africa). no. 95031, pp. 48-50.

[15] Feng, D., D. Caulfield, and A. Sanadi, Effect of compatibilizer on the structure-property relationships of kenaf-fiber/polypropylene composites. Polymer Composites, 2001. 22(4): p. 506-517.

[16] Mohanty, A., M. Misra, and L. Drzl, Surface modification of natural fiber to improve adhesion as reinforcements for thermoset plastics. In The adhesion society. Proceedings of the 24th annual meeting of the adhesion society-adhesion science for the 21st century. February 25-28, 2001. Williamsburg, Virginia, p. 418-420.

[17] Ishak, M., Z. Leman, S. Sapuan, A. Edeerozey, and I. Othman, Mechanical properties of kenaf bast and core fibre reinforced unsaturated polyester composites. In IOP Conference Series: Materials Science and Engineering, 2010. Philadelphia, USA: IOP Publishing, 11(1): p. 012006.

[18] Saad, M.J., Effect of maleated polypropylene (MAPP) on the tensile, impact and thickness swelling properties of kenaf core-polypropylene composites. Journal of Science and Technology, 2010. 2(1): p. 33- 44

[19] Juan, P., P. Naughton, R. Lee, and F. Krabbenborg, Evolution of instrument panels made of polypropylene. 1998, (No. 980067). SAE Technical Paper.

[20] Gupta, A., A. Kumar, A. Patnaik, and S. Biswas, Effect of different parameters on mechanical and erosion wear behavior of bamboo fiber reinforced epoxy composites. International Journal of Polymer Science, 2011. 2011: p. 1-10

[21] Ferrigno, T., H. Katz, and J. Milewski, Cellulose Nanocomposites. In HS Katz and JV Milewski (Eds.), Handbook of fillers and reinforcements for plastics (p. 11-58). New York: Van Nos trand Reinhold Co, 1978. 